\title{
Open-field sex differences prior to puberty in rats
}

\author{
FRED P. VALLE and BORIS GORZALKA \\ University of British Columbia, Vancouver, British Columbia V6T 1W5, Canada
}

\begin{abstract}
Female rats locomoted more, were less thigmotactic, and defecated less than males during open-field tests. These sex differences were observed several days before the occurrence of puberty in the females. Thus, sex differences in open-field locomotion follow a different developmental pattern than do sex differences in activity wheel locomotion, which appear only after puberty. This suggests that open-field locomotion and activity wheel locomotion are not expressions of the same underlying neural organization but are, rather, expressions of different neural programs.
\end{abstract}

Mature female rats typically locomote more, rear more, leave the peripheral wall more (are less thigmotactic), and defecate less in an open field than do mature males. Several investigators have attributed these behavioral sex differences to the effects of ovarian hormones on the female's brain (see review by Archer, 1975). In part, this hypothesis is advanced because (1) openfield locomotion scores of mature females are higher at estrus, when levels of endogenous ovarian hormones are high, than at diestrus, when such levels are low (e.g., Birke \& Archer, 1975), and (2) injections of exogenous ovarian hormones also produce an increase in openfield locomotion in mature female rats (e.g., Slater \& Blizard, 1976). Similarly, injections of estrogen in mature female rats produce a rapid decrease in food consumption and, consequently, in defecation frequency (Slater \& Blizard, 1976).

Estrogen injections in prepubertal rats, however, do not produce decreases in food intake (Wade \& Zucker, 1970). Indeed, it has been suggested that prepubertal females, who eat just as much as their male litter mates, have a higher level of plasma estrogen than they do subsequent to puberty, when estrogen produces its inhibitory effect on their food consumption (Weisz \& Gunsalus, 1973). To account for this pattern, it has been suggested that certain critical neural and/or hormonal changes occur at puberty that permit estrogen to have the inhibitory effect on hunger that is typical of the postpubertal female (Wade, 1976).

It has also been reported that running in activity wheels follows this same developmental pattern; that is, estrogen affects (increases) running after puberty in female rats but has no effect before puberty (Kennedy, 1964; Porterfield \& Stern, 1974). Because effects obtained with rats in activity wheels sometimes do not

This research was supported by a grant to F. P. Valle from the Natural, Applied and Health Science Grants Committee of the University of British Columbia. Aspects of the data were discussed at the nineteenth annual meeting of the Psychonomic Society, San Antonio, 1978. show up in other measures of general activity (see Bolles, 1975, pp. 217-229), it would be useful to know whether the easily replicable pattern of male-female differences found in open-field situations, differences that are presumed to reflect, primarily, the effects of estrogen on the female's brain, likewise only appear after puberty and thus follow the same developmental sequence as do sex differences in feeding and activity wheel running.

The results of some recent studies suggest that openfield sex differences may differ from those found in feeding and running wheel situations in this regard: These studies report open-field sex differences prior to puberty in rats. Unfortunately, "puberty" was defined solely in terms of days of age in these studies. For example, Stewart, Skvarenina, and Pottier (1975), in two experiments, obtained greater locomotion scores and smaller thigmotactic scores in "prepubescent" females compared with males, but "prepubescent" was defined simply as 30 days of age. Stevens and Goldstein (1978) obtained significant open-field sex differences "both before and after puberty," which they defined as 45 and 85 days of age, respectively. And, while Blizard, Lippman, and Chen (1975) did not obtain a significant activity difference between 41-dayold males and females, they did obtain a significant difference with "peripuberal" animals, animals of 52 days of age. Since the onset of puberty in rats varies as a function of strain (Bennett \& Vickery, 1970) and rearing conditions (e.g., Erskoff, 1952; Fiske, 1941), it is inappropriate to use days of age as a criterion of pubertal status. Therefore, while these studies demonstrate that open-field sex differences are present in young rats, they do not necessarily show that openfield sex differences are present in prepubertal rats. The results of these studies are, therefore, inconclusive with respect to the relationship between open-field sex differences and the occurrence of puberty in rats.

In the present study, puberty in female rats was assessed by (1) the opening of the vaginal introitus, an event that coincides with the onset of ovulation and 
estrus in rats (Hafez, 1970; Kennedy \& Mitra, 1963), and (2) the appearance of significantly lower body weights in the females. Body weight has been found to be an especially sensitive index of estrogen levels in postpubertal rats: Food consumption and body weights are significantly depressed in females by levels of estrogen too low to produce cornification of the vaginal smear (Drewett, 1973). If open-field sex differences follow the same developmental pattern as running wheel sex differences, the appearance of the female pattern of open-field behavior-more locomotion and rearing, less thigmotaxis and defecation-should coincide with the opening of the introitus and the appearance of bodyweight differences.

\section{METHOD}

The 10 male and 10 female rats were purchased from the Woodlyn Laboratories, Ltd., Guelph, Ontario. They were 22 days old upon arrival in the laboratory, at which time they were housed in like-sex group cages, five animals per cage. The rats' tails were marked with colored ink for identification, and the animals were weighed and handled daily throughout the experiment. Beginning at 28 days of age, each animal received one 3-min test in the open field every other day. The open field was a white, $1.22-\mathrm{m}$ square arena with a floor divided by black lines into 16 equal squares. On each test, a record was kept of (1) the number and sequence of squares the animal entered, (2) the number of times the animal reared, and (3) the number of boli the animal defecated. The open-field tests were conducted beginning at $2200 \mathrm{~h}, 3 \mathrm{~h}$ after the onset of the 12-h dark cycle.

Prior to each open-field test, during the daily handling, it was noted which females had an opened vaginal introitus. The investigator who checked for vaginal opening (B.G.) was unaware of the open-field results, and the investigator who scored the open-field tests (F.V.) was unaware of the state of the vaginal introitus.

\section{RESULTS}

Table 1 presents for males and females: (1) the mean number of squares entered on each of 10 open-field tests (and the standard error of the mean, SEM), (2) the mean body weight prior to each test (and the SEM), and (3) the number of females whose introitus had opened by the time of each test. Also reported in Table 1 are the results of one-tailed tests of the significance of male-female differences. One-tailed tests were used to increase the power of the analyses in detecting greater levels of activity and lesser body weights in the females.

It can be seen in Table 1 that females locomoted significantly more than males on the first open-field test (at 28 days of age) and on all subsequent tests. None of the females had an opened vaginal introitus at the time of the first test, and no significant difference between male and female body weights existed at the time of the first test. The first significant body-weight difference did not appear until 32 days of age (at which time 2 out of 10 females had an opened introitus), and consistently
Table 1

Results of 10 Open-Field Tests, Showing the Mean Number of Squares Entered and the Mean Body Weight (in Grams) on the Day of the Test for Male and Female Rats and the Number of Females Whose Vaginal Introitus Had Opened (VIO) by the Time of the Test

\begin{tabular}{|c|c|c|c|c|c|c|c|c|c|}
\hline \multirow[b]{3}{*}{ Age } & \multicolumn{4}{|c|}{ Squares Entered } & \multicolumn{4}{|c|}{ Body Weight } & \multirow[b]{3}{*}{ VIO } \\
\hline & \multicolumn{2}{|c|}{ Males } & \multicolumn{2}{|c|}{ Females } & \multicolumn{2}{|c|}{ Males } & \multicolumn{2}{|c|}{ Females } & \\
\hline & Mean & SEM & Mean & SEM & Mean & SEM & Mean & SEM & \\
\hline 28 & 32 & 4.0 & 44 & $4.5^{*}$ & 67 & 1.2 & 65 & 1.3 & 0 \\
\hline 30 & 45 & 5.2 & 62 & $4.6^{*}$ & 77 & 1.6 & 75 & 1.6 & 0 \\
\hline 32 & 39 & 4.4 & 47 & $4.7 \dagger$ & 88 & 2.2 & 82 & $2.0^{*}$ & 2 \\
\hline 34 & 42 & 3.9 & 64 & $4.8 \dagger$ & 100 & 2.5 & 95 & 2.1 & 7 \\
\hline 36 & 52 & 5.0 & 64 & $3.6^{*}$ & 114 & 3.1 & 106 & $2.4^{*}$ & 8 \\
\hline 38 & 45 & 4.3 & 75 & $7.0^{*}$ & 128 & 3.3 & 114 & $2.7 \dagger$ & 10 \\
\hline 40 & 50 & 3.5 & 72 & $3.9 \dagger$ & 141 & 3.7 & 125 & $2.8 \dagger$ & 10 \\
\hline 42 & 56 & 4.4 & 72 & $4.5 \dagger$ & 157 & 4.3 & 135 & $3.0 \dagger$ & 10 \\
\hline 44 & 57 & 4.0 & 70 & $5.4^{*}$ & 171 & 4.8 & 146 & $2.4 \dagger$ & 10 \\
\hline 46 & 47 & 3.4 & 68 & $5.3 \dagger$ & 184 & 4.9 & 146 & $2.9 \dagger$ & 10 \\
\hline
\end{tabular}

Note-Age refers to age in days at time of test.

*Male-female difference significant at $p<.05$ (one-tailed test). tMale-female difference significant at $p<.01$ (one-tailed test).

significant differences in body weight did not appear until 35-36 days of age (when 8 out of 10 females had an opened introitus).

With respect to data not reported in Table 1, males defecated more than females on the first open-field test [respective means, 4.4 and 1.6 boli; $\mathrm{t}(18)=2.75$, $\mathrm{p}<.025$, one-tailed test] and on the second test [respective means, 3.6 and 1.5 boli; $\mathrm{t}(18)=1.93$, $\mathrm{p}<.05$, one-tailed test]. No subsequent significant differences in number of boli were found. The modal and median number of boli for both groups were 0 from the fourth test on.

Females were less thigmotactic (i.e., were more inclined to leave the peripheral wall of the open field and enter the central squares) than males, as measured by the thigmotactic ratio (number of central squares entered divided by total number of squares entered). The difference was significant over all 10 tests combined and, individually, on the first and third tests $(p<.05$, one-tailed tests).

Unlike the above three measures, significant differences in rearing activity (females rearing more than males) did not appear until the fifth test (36 days of age), when most females had begun to cycle, and subsequently appeared on the sixth and eighth tests.

\section{DISCUSSION}

The results of this study show that sex differences are present in rats on at least three measures of open-field activity several days before the occurrence of puberty in the females. This finding is not inconsistent with the hypothesis that the female pattern of open-field activity reflects the effects of estrogens on the female's brain. Prepubertal female rats have plasma estrogens of both an adrenal and a gonadal origin, and the levels of these estrogens may be higher than those that occur subsequent to puberty (Morera, Audi, Bertrand, \& Saez, 1978; Weisz \& Gunsalus, 1973). 
What these data do indicate is that the neural systems responsible for these female patterns of open-field activity are responsive to the varieties of estrogen that are present before the occurrence of puberty, unlike those systems that underlie running wheel activity and only become responsive to estrogens after the occurrence of puberty. Thus, these results suggest that separate neural systems, with different developmental programs, underlie locomotion in the activity wheel and locomotion in the open field. To the extent that this inference is valid, it suggests that the choice of the situation to use in order to measure the effects of hormone conditions (or other variables) on "locomotor activity" is not a matter of convenience but a decision that involves choosing between two quite different behavioral systems. Conclusions similar to this have been suggested by others who have noted the lack of correlation between activity wheel scores and other measures of locomotor activity (Bolles, 1975; Cofer \& Appley, 1964). Anderson (1937), for example, correlated running wheel scores with locomotor scores from a Dashiell maze and found a correlation of .12. By contrast, in an unpublished study in our laboratory, the correlation coefficient between open-field locomotion and Dashiell-maze locomotion for nine adult male rats was .67. Perhaps running wheel activity is primarily thermoregulatory (McLean \& Coleman, 1971; Stevenson \& Rixon, 1957), whereas open-field activity is primarily exploratory in nature. It might be noted, in this regard, that exogenous estrogen injections lower body temperatures in mature, ovariectomized female rats (Nieburgs \& Greenblatt, 1948) and, during that stage of the estrous cycle when estrogen levels are highest in nonovariectomized females, there is approximately a $1^{\circ} \mathrm{C}$ drop in body temperature and this drop is more pronounced in females whose activity is restricted (McLean \& Coleman, 1971).

Another important finding in the present study is the sex difference in defecation frequency that occurred before puberty in the females. The significant fact here is that defecation differences were found in the absence of body-weight differences. Several authors (e.g., Slater \& Blizard, 1976) have suggested that the reason mature females defecate less than males is because the females' food intake is depressed by estrogen, and hence they have less colonic material to eliminate. While this explanation may be at least partly valid for postpubertal females, in which estrogen suppresses food intake, it is not adequate to explain the threefold difference in defecation found in the present study between prepubertal male and female rats who weighed the same amount. As noted earlier, estrogen does not depress food consumption in prepubertal females (Wade, 1976). An implication of the present results is that female rats are simply less inclined to defecate in open-field situations than are males, regardless of the amount of material available for elimination. Perhaps this sexual dimorphism is related, ultimately, to different selection pressures having acted on male and female rats with respect to odor marking and/or predator avoidance.

Finally, it should be noted that at least one male-female open-field activity difference did not appear until after most females had reached puberty. Females did not rear significantly more than males until 36 days of age, when 8 out of 10 females had an opened introitus and significant body-weight differences had appeared. These data suggest that sex differences in rearing follow a developmental progam that is more analogous to those that appear in activity wheel locomotion than to those that appear in other aspects of open-field behavior. Questions about the functional significance of these developmental differences remain to be answered.

\section{REFERENCES}

Anderson, E. E. Interrelationship of drives in the male albino rat: I. Intercorrelation of measures of drives. Journal of Comparative Psychology, 1937, 24, 73-118.

Archer, J. Rodent sex differences in emotional and related behavior. Behavioral Biology, 1975, 14, 451-479.
Bennett, S. P., \& Vickery, B. H. Rats and mice. In E. S. E. Hafey (Ed.), Reproduction and breeding techniques for laboratory animals. Philadelphia: Lea \& Febiger, 1970.

Birke, L. I. A., \& Archer, J. Open-field behaviour of oestrous and diestrous rats: Evidence against an "emotionality" interpretation. Animal Behaviour, 1975, 23, 509-512.

Blizard, D. A., Lippman, H. R., \& Chen, J. J. Sex differences in open-field behavior in the rat: The inductive and actuational role of gonadol hormones. Physiology \& Behavior, 1975, 14, 601-608.

Bolles, R. C. Theory of motivation (2nd. ed.). New York: Wiley, 1975.

Cofer, C. N., \& Appley, M. H. Motivation: Theories and Research. New York: Wiley, 1964.

Drewett, R. F. Oestrous and dioestrous components of the ovarian inhibition of hunger in the rat. Animal Behaviour, 1973, 21, 772-780.

ERSKofF, B. H. Nutrition and the anterior pituitary with special reference to the general adaptation syndrome. Vitamins and Hormones, 1952, 10, 79-140.

Fiske, V. M. Effect of light on sexual maturation, estrous cycles, and anterior pituitary of the rat. Endocrinology, 1941, 29, 107-196.

HAFEz, E. S. E. Female reproductive organs. In E. S. E. Hafez (Ed.), Reproduction and breeding techniques for laboratory animals. Philadelphia: Lea \& Febiger, 1970.

Kennedy, G. C. Hypothalamic control of the endocrine and behavioral changes associated with oestrus in the rat. Journal of Physiology (London), 1964, 172, 383-392.

Kennedy, G. C., \& Mitra, J. Body weight and food intake as initiating factors for puberty in rats. Journal of Physiology, $1963,66,408-418$.

Mclean, J. H., \& Coleman, W. P. Temperature variation during the estrous cycle: Active vs restricted rats. Psychonomic Science, 1971, 22, 179-180.

Morera, A. M., Audi, L., Bertrand, J., \& Saez, J. M. Estrogen-like compounds and progesterone in male and female rats before puberty-I. Pattern and origin. Journal of Steroid Biochemistry, 1978, 9, 623-629.

Nieburgs, H. E., \& Greenblatt, R. B. The role of the endocrine gland in body temperature regulation. Journal of Clinical Endocrinology, 1948, 8, 622-623.

Porterfield, A. L., \& Stern, J. J. Growth hormone and the refractoriness of the prepubertal activity system to estradiol in the rat. Physiological Psychology, 1974, 2, 23-25.

Slater, J., \& Blizard, D. A. A reevaluation of the relation between estrogen and emotionality in female rats. Journal of Comparative and Physiological Psychology, 1976, 90, 755-764.

Stevens, R., \& Goldstein, R. Effects of neonatal testosterone and progesterone on open-field behaviour in the rat. Quarterly Journal of Experimental Psychology, 1978, 30, 157-166.

Stevenson, J. A., \& Rixon, R. H. Environmental temperature and deprivation of food and water on the spontaneous activity of rats. Yale Journal of Biology \& Medicine, 1957, 29, 575-584.

Stewart, J., Skvarenina, A., \& Pottier, J. Effects of neonatal androgens on open-field behavior and maze learning in the prepubescent and adult rat. Physiology \& Behavior, 1975, 14, 291-295.

WADE, G. N. Sex hormones, regulatory behaviors, and body weight. In J. S. Rosenblatt, R. A. Hinde, E. Shaw, \& C. Beer (Eds.), Advances in the study of behavior (Vol. 6). New York: Academic Press, 1976.

W ADE, G. N., \& ZuCKER, I. Development of hormonal control over food intake and body weight in female rats. Journal of Comparative and Physiological Psychology, 1970, 70, 213-220.

Weisz, J., \& Gunsalus, P. Estrogen levels in immature rats: True or spurious-Ovarian or adrenal? Endocrinology, 1973, 93, 1057-1065.

(Received for publication October 17, 1980.) 